\title{
Association of arterial stiffness with single nucleotide polymorphism rs1333049 and metabolic risk factors
}

Suphawadee Phababpha ${ }^{1}$, Upa Kukongviriyapan ${ }^{1 *}$, Poungrat Pakdeechote ${ }^{1}$, Laddawan Senggunprai ${ }^{2}$, Veerapol Kukongviriyapan ${ }^{2}$, Chatri Settasatian ${ }^{3}$, Pyatat Tatsanavivat ${ }^{4}$, Phongsak Intharaphet ${ }^{4}$, Vichai Senthong ${ }^{4}$, Nantarat Komanasin ${ }^{5}$, Nongnuch Settasatian ${ }^{5}$ and Stephen E Greenwald ${ }^{6^{*}}$

\begin{abstract}
Background: Increased arterial stiffness is a cardiovascular outcome of metabolic syndrome (MetS). The chromosome 9p21 locus has been identified as a major locus for risk of coronary artery disease (CAD). The single nucleotide polymorphism (SNP), rs1333049 on chromosome 9p21.3 has been strongly associated with CAD and myocardial infarction. Increased arterial stiffness could be the link between the 9p21 polymorphism and increased cardiovascular risk. Since the impact of a genetic polymorphism on arterial stiffness especially in Asian populations has not been well defined, we aimed to investigate the association of arterial stiffness with rs 1333049 variant on chromosome 9p21.3 in Thai subjects with and without MetS risk factors.

Methods: A total of 208 Thai subjects, aged 35-75 years, 135 with and 73 without MetS, according to IDF and NCEP-ATPIII criteria, were included in this study. Aortic-femoral pulse wave velocity (afPWV), brachial-ankle pulse wave velocity (baPWV) and aortic ankle pulse wave velocity (aaPWV) were measured and used as markers of arterial stiffness. The chromosome 9p21.3 locus, represented by the rs 1333049 variant and blood biochemistry were evaluated.

Results: Arterial stiffness was elevated in subjects with MetS when compared with nonMetS subjects. PW, especially afPW increased progressively with increasing number of Met $S$ risk factors $(r=0.322, P<0.001)$. We also found that the frequency distribution of the rs1333049 genotypes is significantly associated with the afPW $(\mathrm{P}<0.05)$. In multivariate analyses, there was an association between homozygous $C$ allele and afPWV (Odds ratio (OR), 8.16; 95\% confidence interval $(C \mathrm{Cl}), 1.91$ to 34.90 ; $\mathrm{P}=0.005)$, while the $\mathrm{GC}$ genotype was not related to afPW $(\mathrm{OR}, 1.79 ; 95 \% \mathrm{Cl}, 0.84$ to $3.77 ; \mathrm{P}=0.129)$ when compared with the $\mathrm{GG}$ genotype.
\end{abstract}

Conclusions: Our findings demonstrate for the first time that arterial stiffness is associated with genetic polymorphism in 9p21 and metabolic risk factors in a Thai population.

Keywords: Metabolic syndrome, Pulse wave velocity, Arterial stiffness, Chromosome 9p21.3, Single nucleotide polymorphism rs 1333049

\footnotetext{
* Correspondence: upa_ku@kku.ac.th; s.e.greenwald@qmul.ac.uk

'Department of Physiology, Faculty of Medicine, Khon Kaen University, Khon Kaen, Thailand

${ }^{6}$ Blizard Institute, Barts \& The London School of Medicine \& Dentistry, Queen

Mary University of London, London, United Kingdom

Full list of author information is available at the end of the article
} 


\section{Background}

Metabolic syndrome (MetS) is defined as a clustering of metabolic abnormalities including central obesity, hyperglycaemia, dyslipidaemia, hypertriglyceridaemia, and elevated blood pressure [1]. MetS is now a major public health problem with high prevalence in both developed and developing countries [2]. Current estimates suggest that, worldwide, about $20-30 \%$ of the population have some form of this syndrome [3]. In Thailand, by 2006, the prevalence of the MetS was about 19\% in men and $27 \%$ in women [4]. Although environmental risk factors contribute greatly to the development of MetS, genetic factors also play an important role in its pathogenesis [5-8]. A previous study in a Caribbean-Hispanic population found that genetic factors contribute $24 \%$ to the MetS after adjusting for age and sex [9]. In the past year, several genome wide association studies have reported associations between a region on chromosome 9p21.3 and risk of cardiovascular disease (CVD) [5]. The same chromosomal region is also associated with type 2 diabetes (T2D) [10]. MetS is strongly associated with the risk of CVD and T2D [11]. People with MetS have higher all cause and cardiovascular mortality than those without MetS.

Increased arterial stiffness, a pathological condition associated with vascular damage and or remodelling, is a cardiovascular outcome of MetS [12-14]. It has been shown to predict CVD morbidity and mortality in the general population and also in T2D [12]. The SNP rs1333049 on chromosome 9p21.3 has a particularly strong association with carotid plaque formation [15], abdominal aortic aneurysm [16], and predicts severity of CAD [17]. Although the effect of MetS and its components on arterial stiffness has been reported in the past, this association has not been addressed in a Thai population. Moreover, there has been little work describing the association of genetic variation on chromosome 9p21.3 with arterial stiffness, especially in Asian nationals [18]. To shed light on a possible influence of these genetic polymorphisms on arterial wall integrity, it is therefore the aim of this study to investigate the association of rs 1333049 variant on chromosome 9p21 and arterial stiffness in Thais with and without MetS risk factors.

\section{Methods}

\section{Study population}

A total of 208 subjects, 117 men and 91 women, aged 35-75 years, were recruited from the Outpatient Clinic of Queen Sirikit Heart Center of Northeast Thailand, Faculty of Medicine, Khon Kaen University, Khon Kaen Province, Thailand. MetS was defined using a combination of the International Diabetes Federation (IDF) and National Cholesterol Education Program Adult Treatment Panel III (NCEP-ATPIII) criteria, with modification of waist circumference (WC) for Asians [3,19,20]. This definition requires at least three of the following components: (1) central obesity (WC $\geq 90 \mathrm{~cm}$ in men, and $\geq 80 \mathrm{~cm}$ in women), (2) triglyceride concentration $\geq 150 \mathrm{mg} / \mathrm{dL}$ or on triglyceride-lowering medication, (3) high-density lipoprotein cholesterol (HDL-c) $<40 \mathrm{mg} / \mathrm{dL}$ in men and $<50 \mathrm{mg} / \mathrm{dL}$ in women or on medication for low HDL-cholesterol, (4) systolic blood pressure $\geq 130$ $\mathrm{mmHg}$ and/or diastolic blood pressure $\geq 85 \mathrm{mmHg}$ or on antihypertensive medication, and (5) fasting glucose concentration $\geq 100 \mathrm{mg} / \mathrm{dL}$ or drug treatment for elevated glucose. NonMetS (healthy) individuals were defined as those without history or diagnosis of MetS.

Informed consent was obtained from each participant. The study protocol was approved by the Ethics Committee for Human Research of Khon Kaen University (HE510414) and the study was conducted in accordance with the Declaration of Helsinki.

\section{Blood sample collection and anthropometric parameters}

After 12-hour overnight fasting, blood was drawn from an antecubital vein in the morning, and sent for analysis within 3 hours. Biochemical markers in serum such as fasting glucose, lipid profiles, and uric acid were analysed by a Hitachi 917 automatic analyser (Roche Diagnostics, Basel, Switzerland) at the Clinical Laboratory Unit of Queen Sirikit Heart Center of Northeastern Thailand. High sensitivity C-reactive protein (hsCRP) concentration was determined by means of high sensitivity particle enhanced immunonephelometry using the BN ProSpec ${ }^{\circledR}$ System (Siemens Healthcare Diagnostics Products GmbH, Marburg, Germany). Fasting serum insulin was determined by a sandwich immunoassay with commercial kits (Cisbio Bioassays, MA, USA). Insulin resistance was estimated using the homeostasis model assessment of insulin resistance (HOMA-IR) index, calculated from the following expression: HOMA-IR = fasting insulin $(\mu \mathrm{U} / \mathrm{mL}) x$ fasting plasma glucose $(\mathrm{mmol} / \mathrm{L}) / 22.5$. Body mass index (BMI) was calculated as weight $(\mathrm{kg})$ divided by height $(\mathrm{m})^{2}$. WC was measured midway between the inferior margin of the last rib and the iliac crest. Blood pressure was measured in the left arm of supine subjects after 15 minutes of rest, using a Dinamap Carescape v100 (GE Medical System, WI, USA).

\section{Pulse wave velocity measurement}

After blood pressure measurement, PWV was measured according to a previously described method [21] using a custom-built data acquisition system (Arterial Compliance Monitor, Barts and The London's School of Medicine and Dentistry, UK), compatible with commercial continuous wave Doppler probes (Dopplex MDII, Huntleigh Healthcare, Cardiff, UK) and custom-made reflectance photoplethysmography (PPG) probes. PWV 
was measured by placing two pulse sensing probes at either end of arterial segment under study. Aortic-femoral pulse wave velocity (afPWV), a good marker of aortic stiffness, was measured by placing the proximal Doppler probe $(4 \mathrm{MHz})$ in the supraclavicular fossa of the subject's neck at $45^{\circ}$ to the subclavian arterial wall, angled so that the ultrasound beam was directed toward the aortic arch. The distal probe (reflectance PPG) was placed over the femoral artery near the inguinal ligament. For brachial-ankle pulse wave velocity (baPWV), the two PPG probes were placed over the brachial artery and dorsalis pedis artery, respectively. For the aortic-ankle pulse wave velocity (aaPWV), the proximal Doppler probe $(4-\mathrm{MHz})$ was placed in the supraclavicular fossa and the distal PPG probe was placed on the foot over the dorsalis pedis artery. The pulse-wave contours from the proximal and distal probes were captured at a sample rate of $1 \mathrm{kHz}$ and recorded for at least $3 \mathrm{~min}$. Data were analysed offline by custom-written software to detect the feet of the proximal and distal pulse waves and to measure the time delay between them. Knowing the distance between the proximal and distal sites and the propagation time delay between the artery waveforms, PWV was calculated and expressed as $\mathrm{m} / \mathrm{s}$. We have previously found [21] that the coefficients of variation values of PWV between the intra- and inter-day measurements were less than $5 \%$.

\section{DNA preparation and genotyping}

The genotyping was performed in 171 subjects and these were taken as a representative sample of the entire study population. DNA was extracted from EDTA treated blood samples using a Genomic DNA mini kit (Geneaid, Taiwan) according to the manufacturer's protocol. Genotyping for rs1333049 was performed using the TaqMan SNP allelic discrimination genotyping assay (Applied Biosystems, CA, USA). A total of 20 ng purified DNA was amplified in a final volume of $20 \mu \mathrm{L}$ per well in 96 well plates. The PCR conditions were; initial denaturation at $95^{\circ} \mathrm{C}$ for $10 \mathrm{~min}$, followed by 40 cycles at $92^{\circ} \mathrm{C}$ for $15 \mathrm{sec}$ and $60^{\circ} \mathrm{C}$ for $1 \mathrm{~min}$. Post PCR allelic discrimination was carried out by measuring allele-specific fluorescence on an ABI prism ${ }^{\circledR} 7500$ Sequence Detection System (Applied Biosystems) using the Sequence Detection System software version 1.1. Genotyping was successful in $96 \%$ of rs1333049 polymorphism.

\section{Statistical analyses}

Statistical comparison between MetS and nonMetS groups was assessed by Student's $t$-test or the MannWhitney $U$ test as appropriate. Pearson correlation analysis was used to assess relationships between PWV and anthropometric variables, and also between PWV and blood biochemistry. Comparisons among three or more groups were evaluated by one way analysis of variance (ANOVA) followed by Newman-Keuls post-hoc analysis. Multiple logistic regression analysis was employed to identify the risk factors associated with afPWV. Statistical analyses were performed with Stata version 10 (Stata Corp., College Station, TX, USA). A value of $P<0.05$ was considered as significant.

\section{Results}

\section{Characteristics of the study population}

The baseline characteristics of subjects are shown in Table 1 . Their mean age was of $59.5 \pm 10.3$ years (range 35 to 75$), 117$ (56\%) participants were male. Among them, 135 participants were classified as MetS and 73, as nonMetS. According to the IDF and NCEP-ATPIII criteria, WC, systolic blood pressure, triglyceride, fasting blood glucose, insulin, HOMA-IR were higher whereas HDL-cholesterol was lower in MetS subjects. Moreover, age, BMI, pulse pressure, and some parameters of blood biochemistry, including hsCRP and uric acid were significantly higher in MetS than nonMetS subjects.

\section{PWV and relationship between anthropometry and blood biochemistry}

PWV values of each arterial segment (i.e. baPWV, aaPWV, and afPWV) were significantly higher in MetS than nonMetS subjects (Table 2). PWV at all three sites was significantly correlated with age, systolic blood pressure, and WC (Table 3). However, afPWV was more strongly correlated with variables such as BMI, fasting glucose, HOMA-IR, hsCRP and uric acid (Table 3) than the PWV values measured in the arm and the leg. To discern the relationship between PWV and MetS, the relationship between PWV and the number of metabolic risk factors for MetS was analysed, i.e. the presence of insulin resistance, high blood pressure, high triglyceride, low HDL-c, and high WC. baPWV, aaPWV and afPWV increased with increasing number of MetS risk factors (Figure 1). afPWV and aaPWV were significantly correlated with the number of MetS risk factors, the strongest correlation being with afPWV.

\section{Polymorphism of rs1333049 in relation to PWV}

The polymorphism of $\mathrm{rs} 1333049 \mathrm{G}>\mathrm{C}$ has been reported to be associated with increased risk of CVD. We wished to determine whether the SNP could affect arterial elasticity and thus subsequently increase the likelihood of symptomatic CVD. The SNP rs1333049 G>C was analysed in 171 subjects (114 MetS and 57 nonMetS). The frequencies of the $\operatorname{rs} 1333049$ " $G$ " and " $C$ " alleles in all subjects were $66.5 \%$ and $33.5 \%$, respectively. In MetS subjects, the frequencies of the " $G$ " and " $C$ " alleles were $68.5 \%$ and $31.4 \%$, respectively and were not significantly different from nonMetS subjects. In all subjects taken 
Table 1 Characteristics of the study subjects

\begin{tabular}{|c|c|c|c|c|}
\hline Parameters & All subjects $(n=208)$ & NonMetS $(n=73)$ & MetS $(n=135)$ & $P$ value \\
\hline Age (y) & $59.5 \pm 10.3$ & $55.3 \pm 11.3$ & $61.7 \pm 9.0$ & $<0.001$ \\
\hline Gender (male (\%)) & $117(56)$ & $47(64)$ & $70(52)$ & 0.136 \\
\hline Waist circumference $(\mathrm{cm})$ & $88.6 \pm 10.4$ & $81.3 \pm 9.5$ & $92.5 \pm 8.5$ & $<0.001$ \\
\hline Body mass index $\left(\mathrm{kg} / \mathrm{m}^{2}\right)$ & $25.0 \pm 3.7$ & $23.1 \pm 3.2$ & $26.1 \pm 3.4$ & $<0.001$ \\
\hline Systolic blood pressure (mmHg) & $129 \pm 17.0$ & $121 \pm 11.2$ & $134 \pm 17.7$ & $<0.001$ \\
\hline Diastolic blood pressure (mmHg) & $73.6 \pm 11.1$ & $71.8 \pm 9.6$ & $74.6 \pm 11.8$ & 0.084 \\
\hline Pulse pressure $(\mathrm{mmHg})$ & $55.7 \pm 13.7$ & $48.7 \pm 9.3$ & $59.5 \pm 14.2$ & $<0.001$ \\
\hline Heart rate (beats/min) & $66.4 \pm 12.0$ & $66.4 \pm 13.8$ & $66.4 \pm 11.0$ & 0.880 \\
\hline Total cholesterol (mg/dL) & $184 \pm 45.9$ & $180 \pm 45.7$ & $186 \pm 46.0$ & 0.396 \\
\hline Triglyceride (mg/dL) & $181 \pm 104$ & $132 \pm 66.0$ & $208 \pm 112$ & $<0.001$ \\
\hline HDL-cholesterol (mg/dL) & $43.7 \pm 12.6$ & $48.7 \pm 13.3$ & $41.0 \pm 11.4$ & $<0.001$ \\
\hline LDL-cholesterol (mg/dL) & $104 \pm 38.6$ & $105 \pm 40.9$ & $104 \pm 37.4$ & 0.805 \\
\hline Fasting glucose (mg/dL) & $108 \pm 45.9$ & $89.9 \pm 17.0$ & $119 \pm 53.2$ & $<0.001$ \\
\hline Insulin ( $\mu \mid \mathrm{U} / \mathrm{mL})$ & $16.2 \pm 9.6$ & $13.3 \pm 7.8$ & $17.8 \pm 10.1$ & $<0.001$ \\
\hline HOMA-IR & $4.65 \pm 4.6$ & $2.96 \pm 1.9$ & $5.58 \pm 5.3$ & $<0.001$ \\
\hline hsCRP (mg/L) & $1.79 \pm 2.0$ & $1.44 \pm 1.6$ & $1.98 \pm 2.1$ & 0.015 \\
\hline Uric acid (mg/dL) & $6.32 \pm 1.8$ & $5.90 \pm 2.0$ & $6.54 \pm 1.7$ & 0.003 \\
\hline
\end{tabular}

All data are expressed as mean \pm SD or number (\%). $H D L$, high-density lipoprotein; $L D L$, low-density lipoprotein; HOMA-IR, homeostatic model assessment-insulin resistance; $h S C R P$, high sensitivity $C$ reactive protein. $P$ value, nonMetS vs. MetS.

together, the frequency of the genotypes GG, GC and CC were $46 \%, 41 \%$ and $13 \%$, respectively, the distribution being consistent with the Hardy-Weinberg equilibrium, with Chi-squared $=0.769, \mathrm{P}=0.681$.

The influence of rs1333049 polymorphism on arterial elasticity was analyzed. There was an association of rs1333049 genotypes with afPWV, but not with baPWV or aaPWV. The effect of this was further analysed by assigning subjects to a 'low' group if their PWV was less than or equal to $11.0 \mathrm{~m} / \mathrm{s}$ (based on the mean afPWV of nonMetS subjects) and to a 'high' group, if greater than $11.0 \mathrm{~m} / \mathrm{s}$. The genotype of rs1333049 distribution in the low and high PWV subjects is shown in the Table 4. The distribution was significantly different between the low and high afPWV groups with Chi-squared $=7.45$, $\mathrm{P}<0.05$, suggesting a positive association between the rs1333049 SNP and increased arterial stiffness.

Table 2 Pulse wave velocities of each arterial segment in non-metabolic and metabolic syndrome subjects

\begin{tabular}{llll}
\hline Pulse wave velocity & NonMetS $(\mathbf{n = 7 3 )}$ & MetS $(\mathbf{n = 1 3 5})$ & $\boldsymbol{P}$ value \\
\hline baPW $(\mathrm{m} / \mathrm{s})$ & $10.22 \pm 3.2$ & $11.25 \pm 3.3$ & 0.004 \\
$\mathrm{aaPW}(\mathrm{m} / \mathrm{s})$ & $11.08 \pm 3.2$ & $12.40 \pm 2.8$ & $<0.001$ \\
afPW $(\mathrm{m} / \mathrm{s})$ & $10.64 \pm 4.9$ & $13.88 \pm 5.4$ & $<0.001$ \\
\hline
\end{tabular}

All data are expressed as mean $\pm S D$, baPWV, brachial-ankle pulse wave velocity; aaPWV, aortic-ankle pulse wave velocity; afPWV, aortic-femoral pulse wave velocity. $P$ value, nonMetS vs. MetS.

\section{Multivariate analysis of factors affecting PWV}

Since the effect of age, gender, risk factors and rs1333049 genotypes on PWV was strongest in the aorto-femoral segment, we subjected these data to a more detailed analysis. In univariate tests, afPWV was significantly associated with age, risk factors and genotypes (Table 5). Similarly, in multivariate analysis, increased afPWV was associated with the advance in age and increment in the number of MetS risk factors as

Table 3 Correlations between pulse wave velocities and anthropometric and blood chemistry variables

\begin{tabular}{lccc}
\hline Parameters & baPWV & aaPWV & afPWV \\
\hline Age (years) & $0.291 \dagger$ & $0.358 \dagger$ & $0.277 \dagger$ \\
Systolic blood pressure $(\mathrm{mmHg})$ & $0.212^{*}$ & $0.332 \dagger$ & $0.242 \dagger$ \\
Diastolic blood pressure $(\mathrm{mmHg})$ & 0.153 & 0.140 & 0.139 \\
Waist circumference $(\mathrm{cm})$ & $0.162^{*}$ & $0.197^{*}$ & $0.352 \dagger$ \\
Body mass index $\left(\mathrm{kg} / \mathrm{m}^{2}\right)$ & -0.011 & 0.015 & $0.257 \dagger$ \\
Triglyceride $(\mathrm{mg} / \mathrm{dL})$ & 0.001 & -0.027 & 0.129 \\
HDL-cholesterol $(\mathrm{mg} / \mathrm{dL})$ & -0.065 & -0.074 & -0.114 \\
Fasting glucose $(\mathrm{mg} / \mathrm{dL})$ & -0.041 & 0.060 & $0.172^{*}$ \\
HOMA-IR & -0.012 & 0.108 & $0.166^{*}$ \\
hsCRP $(\mathrm{mg} / \mathrm{L})$ & 0.060 & 0.116 & $0.225^{*}$ \\
Uric acid $(\mathrm{mg} / \mathrm{dL})$ & 0.061 & 0.150 & $0.203^{*}$ \\
\hline
\end{tabular}

HDL, high-density lipoprotein; HOMA-IR, homeostatic model assessment-insulin resistance; $h s C R P$, high sensitivity C-reactive protein; baPWV, brachial-ankle pulse wave velocity; aaPWV, aortic-ankle pulse wave velocity; afPWV, aorticfemoral pulse wave velocity. ${ }^{*} P<0.05 ;+P<0.001$. 


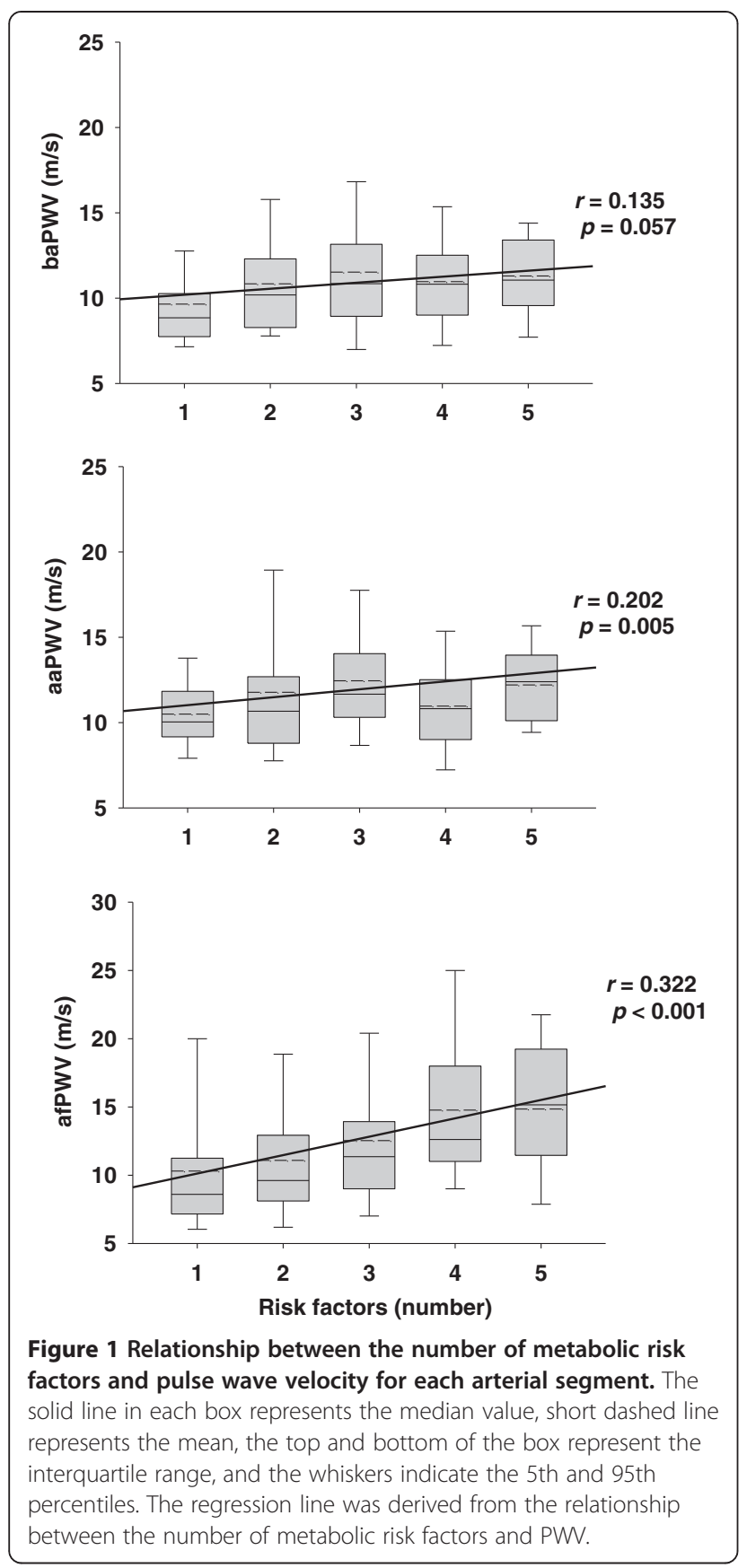

Table 4 Distribution of rs1333049 genotypes in relation to afPWV

\begin{tabular}{lcccc}
\hline \multirow{2}{*}{$\begin{array}{l}\text { Aortic-femoral } \\
\text { pulse wave velocity }\end{array}$} & \multicolumn{3}{c}{ Number subjects (\%) } & Total subjects \\
\cline { 2 - 4 } & GG & GC & CC & \\
\hline$<11 \mathrm{~m} / \mathrm{s}$ & $40(57)$ & $27(39)$ & $3(4)$ & 70 \\
$\geq 11 \mathrm{~m} / \mathrm{s}$ & $39(39)$ & $45(45)$ & $17(17)$ & 101 \\
\hline
\end{tabular}

Chi-square tests of goodness of fit, Chi-square with continuity correction $=7.45$, $\mathrm{P}<0.05$. shown, by the increased OR to 11.12 (95\% CI: 2.20 56.18) when risk factors comprised 5 components. Interestingly, afPWV was also increased in relation to the gene dose ("C") effect (Table 5). The presence of the "GC" or "CC" genotype was associated with increased risk of developing high PWV with OR of 1.79 (95\% CI: 0.84-3.77) and 8.16 (95\% CI: 19.1-34.90) after adjusting for gender, age and metabolic risk factors.

\section{Discussion}

This study demonstrates, for the first time, that SNP rs1333049 on chromosome 9p21.3 is an important determinant for the progression of increasing arterial stiffness, especially that of the aorta, in a Thai population. Increased afPWV and aaPWV are associated with increasing number of MetS risk factors, indicating that a clustering of MetS risk may interact synergistically to affect central arterial stiffness. Previous studies have suggested that arterial stiffening in MetS, particularly in diabetic individuals, is associated with elastic lamellae fragmentation and calcification, increased collagen cross-linking, low-grade inflammation, increased smooth muscle basal tone and endothelial dysfunction [22-25]. These processes may be influenced by both genetic and environmental factors $[6-8,23]$. As the integrity of the aortic wall is dependent on effective load bearing by the elastin collagen network, one could speculate that the SNPs on chromosome 9p21.3 might affect the wall integrity either through increased elastin fracture, degradation due to enhanced matrix metalloprotease activity, calcification or enhanced collagen production.

A previous study has reported that central arterial stiffness, as measured by heart-femoral PWV (hfPWV) was more closely associated with CAD, CVD and peripheral arterial disease than peripheral arterial stiffness [26]. hfPWV, carotid-femoral PWV (cfPWV) and afPWV, as used in this study may all be regarded as measures of 'aortic' stiffness since in all cases the major part of the path traversed by the pulse wave is the aorta and a recent consensus document confirms that cfPWV is an acceptable estimate of aortic stiffness [27]. However, it should be noted that in older people the ascending aorta lengthens with age [28] as does the common iliac artery, which comprises approximately the distal third of the path [29], and this will add an error to the path length measurements, leading to an overestimation of PWV. Previously, a cut-off point of hfPWV at $11.18 \mathrm{~m} / \mathrm{s}$ and cfPWV at $12 \mathrm{~m} / \mathrm{s}$ showed good discrimination in the validation set on the Sphygmocor system and the Colins system, respectively [30]. Deng et al. set a cut-off value of cfPWV at $\geq 9 \mathrm{~m} / \mathrm{s}$ to diagnose arteriosclerosis in patients with essential hypertension [31] and more recently $10 \mathrm{~m} / \mathrm{s}$ has been proposed as the threshold above which there is an increased risk of cardiovascular events [27]. In the 
Table 5 Univariate and multivariate logistic regression models for predicting the central arterial stiffness in the study subjects

\begin{tabular}{|c|c|c|c|c|c|c|}
\hline \multirow[t]{2}{*}{ afPWV } & \multicolumn{3}{|c|}{ Univariate model } & \multicolumn{3}{|c|}{ Multivariate model } \\
\hline & Odds ratio & $95 \% \mathrm{Cl}$ & $P$ & Odds ratio & $95 \% \mathrm{Cl}$ & $P$ \\
\hline Gender Female: Male & 0.812 & $0.44-1.49$ & 0.50 & 0.75 & $0.35-1.58$ & 0.50 \\
\hline \multicolumn{7}{|l|}{ Age } \\
\hline Quartile 1 ( $\leq 51$ years) & 1 & & & 1 & & \\
\hline Quartile 2 (52-59 years) & 4.06 & $1.71-9.61$ & 0.001 & 2.27 & $0.81-6.36$ & 0.120 \\
\hline Quartile 3 (60-66 years) & 4.71 & $1.85-11.99$ & 0.001 & 2.55 & $0.78-8.40$ & 0.123 \\
\hline Quartile 4 ( $\geq 67$ years) & 11.69 & $4.24-32.24$ & $<0.001$ & 7.88 & $2.45-25.3$ & 0.001 \\
\hline \multicolumn{7}{|l|}{ Risk factor } \\
\hline$\leq 1$ & 1 & & & 1 & & \\
\hline 2 & 1.83 & $0.63-5.34$ & 0.267 & 1.36 & $0.35-5.23$ & 0.685 \\
\hline 3 & 3.38 & $1.33-8.59$ & 0.011 & 2.42 & $0.74-7.91$ & 0.144 \\
\hline 4 & 7.71 & $2.89-20.55$ & $<0.001$ & 4.49 & $1.33-15.14$ & 0.015 \\
\hline 5 & 10.00 & $2.68-37.38$ & 0.001 & 11.12 & $2.20-56.18$ & 0.004 \\
\hline \multicolumn{7}{|l|}{ rs1333049 } \\
\hline GG genotype & 1 & & & 1 & & \\
\hline GC genotype & 1.71 & $0.89-3.27$ & 0.106 & 1.79 & $0.84-3.77$ & 0.129 \\
\hline CC genotype & 5.81 & $1.58-21.42$ & 0.008 & 8.16 & $1.91-34.90$ & 0.005 \\
\hline
\end{tabular}

afPWV, aortic-femoral pulse wave velocity.

present study, we assessed aortic stiffness in all subjects using the Arterial Compliance Monitor which measures afPWV rather than cfPWV and chose to use our mean value of afPWV $(11 \mathrm{~m} / \mathrm{s})$. This is close to the values recommended in the consensus document and revealed a clear difference in the association between afPWV and rs1333049 genotypes. We found that the frequency distribution of the rs 1333049 genotypes is significantly associated with afPWV groups $(\mathrm{P}<0.05)$. We conclude that, in spite of uncertainties in the precise value of PWV used to dichotomise the data, there is a clear association between polymorphism of rs1333049 and raised arterial stiffness.

In addition to the aforementioned association, we found increased aortic stiffness in subjects homozygous for the C-allele of rs 1333049 on chromosome 9p21.3, after adjusting for age and the number of MetS risk factors. We suggest the SNP rs1333049 might be involved with the progression of raised aortic stiffness in Thais, although the underlying mechanisms by which SNP rs1333049 on chromosome 9p21.3 contributes to this progression remain unclear. Previous studies have suggested that the chromosome 9p21 locus predicts CAD and involves the initiation or facilitation of atherosclerosis [32,33]. Wang et al. demonstrated that rs 1333049 polymorphism is an independent determinant of coronary plaque progression in a Chinese Han population [34]. Moreover, it was found that chromosome 9p21 locus is associated with recurrent myocardial infarction or cardiac death following an acute coronary event [35].
Taken together, the genetic variants in this 9p21 locus increase the risk of CAD by promoting atherosclerosis development and plaque instability.

A large noncoding RNA gene named ANRIL $(C D K N 2 B-A S)$ is expressed in several cells and tissues, where a number of SNPs located at the 5' end including rs1333049 have been suggested to be associated with CAD [36]. The ANRIL gene possibly coordinates transcriptional regulation of 2 cyclin-dependent kinase inhibitors $(p 16 / C D K N 2 A$ and $p 15 / C D K N 2 B)$ under both physiological and pathological conditions. A SNP rs1333049 was located in a $190 \mathrm{~kb}$ region of the high linkage disequilibrium, upstream both of $p 16 / C D K N 2 A$, $p 15 / C D K N 2 B$ and $p 14 / A R F$ that code for $\mathrm{p} 15$ and $\mathrm{p} 16$ and p14ARF [36]. These proteins are involved in cell cycle regulation, and also affect the atherosclerotic process by inhibiting the transformation of tumour growth factor- $\beta$, a well known tumour suppressor protein [37]. SNP rs1333049 has not only been reported to increase the risk of CAD $[38,39]$ but also of abdominal aortic aneurysms $[16,40]$, these diseases being preceded by altered arterial stiffness. Therefore, our finding of the homozygous CC genotype of SNP rs1333049 in subjects with high aortic stiffness is in good agreement with those observed in CVD patients.

\section{Conclusions}

We have observed that the SNP rs1333049 on chromosome 9p21 locus is associated with increased arterial 
stiffness in a Thai population. This association is strengthened by the presence of MetS risk. Research on this genetic polymorphism in a large population is required to investigate this association in more detail. Moreover, a mechanistic study is also needed to clarify the effect of the chromosome 9p21 locus on arterial stiffening. Since MetS-associated arterial stiffening increases cardiovascular risk, our findings add to the evidence that management of MetS to prevent advanced cardiovascular complications is clinically important.

\section{Abbreviations}

MetS: Metabolic syndrome; SNP: Single nucleotide polymorphism; IDF: International Diabetes Federation; NCEP-ATPIII: National Cholesterol Education Program Adult Treatment Panel III; afPWV: Aortic-femoral pulse wave velocity; baPWV: Brachial-ankle pulse wave velocity; aaPWV: Aorticankle pulse wave velocity; HDL-c: High-density lipoprotein cholesterol; LDL-c: Low-density lipoprotein cholesterol; HOMA-IR: Homeostasis model assessment of insulin resistance; BMI: Body mass index; hsCRP: High sensitivity C-reactive protein.

\section{Competing interests}

The authors declare that they have no competing interests.

\begin{abstract}
Authors' contributions
UK and SEG designed the study, analyzed data, reviewed and edited the manuscript. VK performed statistical analysis and edited the manuscript. SP wrote the manuscript and performed experiments. PP, LS, CS, NK and NS performed some experiments. PT, PI and VS participated in research design and were responsible for subjects' recruitment and the clinical report. All authors read and approved the final manuscript.
\end{abstract}

\section{Acknowledgments}

The study was supported by grants from The Office of the Higher Education Commission, the Faculty of Medicine, and the Khon Kaen University Research Fund. Suphawadee Phababpha was supported by a CHE-PhD-SW-SUP Scholarship, Office of the Higher Education Commission, Ministry of Education, Thailand. PWV equipment, travel and training expenses were provided by a British Council PMI2 Grant (\#RC53) to UK and SEG.

\section{Author details}

'Department of Physiology, Faculty of Medicine, Khon Kaen University, Khon Kaen, Thailand. ${ }^{2}$ Department of Pharmacology, Faculty of Medicine, Khon Kaen University, Khon Kaen, Thailand. ${ }^{3}$ Department of Pathology, Faculty of Medicine, Khon Kaen University, Khon Kaen, Thailand. ${ }^{4}$ Department of Medicine and Queen Sirikit Heart Center of the Northeast, Faculty of Medicine, Khon Kaen University, Khon Kaen, Thailand. ${ }^{5}$ Faculty of Associated Medical Sciences, Khon Kaen University, Khon Kaen, Thailand. 'Blizard Institute, Barts \& The London School of Medicine \& Dentistry, Queen Mary University of London, London, United Kingdom.

Received: 6 May 2013 Accepted: 18 June 2013 Published: 21 June 2013

\section{References}

1. Eckel RH, Alberti KG, Grundy SM, Zimmet PZ: The metabolic syndrome. Lancet 2010, 375(9710):181-183.

2. Hildrum B, Mykletun A, Hole T, Midthjell K, Dahl AA: Age-specific prevalence of the metabolic syndrome defined by the International Diabetes Federation and the National Cholesterol Education Program: the Norwegian HUNT 2 study. BMC Public Health 2007, 7:220.

3. Grundy SM: Metabolic syndrome pandemic. Arterioscler Thromb Vasc Biol 2008, 28(4):629-636.

4. Patel A, Huang KC, Janus ED, Gill T, Neal B, Suriyawongpaisal P, Wong E, Woodward M, Stolk RP: Is a single definition of the metabolic syndrome appropriate?-A comparative study of the USA and Asia. Atherosclerosis 2006, 184(1):225-232.
5. McPherson R, Pertsemlidis A, Kavaslar N, Stewart A, Roberts R, Cox DR, Hinds DA, Pennacchio LA, Tybjaerg-Hansen A, Folsom AR, et al: A common allele on chromosome 9 associated with coronary heart disease. Science 2007, 316(5830):1488-1491.

6. Engelen L, Ferreira I, Gaens KH, Henry RM, Dekker JM, Nijpels G, Heine RJ, Hart LM T, Van Greevenbroek MM, Van der Kallen CJ: The association between the -374T/A polymorphism of the receptor for advanced glycation endproducts gene and blood pressure and arterial stiffness is modified by glucose metabolism status: the Hoorn and CoDAM studies. $J$ Hypertens 2010, 28(2):285-293.

7. Ling Y, Li X, Gu Q, Chen H, Lu D, Gao X: A common polymorphism rs3781637 in MTNR1B is associated with type 2 diabetes and lipids levels in Han Chinese individuals. Cardiovasc Diabetol 2011, 10:27.

8. Yang SJ, Lee ST, Kim WJ, Park SE, Park SW, Kim JW, Park CY: Genetic variation in CYP17A1 is associated with arterial stiffness in diabetic subjects. Exp Diabetes Res 2012, 2012:827172.

9. Lin HF, Boden-Albala B, Juo SH, Park N, Rundek T, Sacco RL: Heritabilities of the metabolic syndrome and its components in the Northern Manhattan Family Study. Diabetologia 2005, 48(10):2006-2012.

10. Broadbent HM, Peden JF, Lorkowski S, Goel A, Ongen H, Green F, Clarke R, Collins R, Franzosi MG, Tognoni $G$, et al: Susceptibility to coronary artery disease and diabetes is encoded by distinct, tightly linked SNPs in the ANRIL locus on chromosome 9p. Hum Mol Genet 2008, 17(6):806-814.

11. Cannon CP: Mixed dyslipidemia, metabolic syndrome, diabetes mellitus, and cardiovascular disease: clinical implications. Am J Cardiol 2008, 102(12A):5L-9L.

12. Laurent S, Cockcroft J, Van Bortel L, Boutouyrie P, Giannattasio C, Hayoz D, Pannier B, Vlachopoulos C, Wilkinson I, Struijker-Boudier H: Expert consensus document on arterial stiffness: methodological issues and clinical applications. Eur Heart J 2006, 27(21):2588-2605.

13. Lau KK, Wong YK, Chan YH, Yiu KH, Teo KC, Li LS, Ho SL, Chan KH, Siu CW, Tse HF: Prognostic implications of surrogate markers of atherosclerosis in low to intermediate risk patients with type 2 diabetes. Cardiovasc Diabetol 2012, 11:101.

14. Shin JY, Lee HR, Lee DC: Increased arterial stiffness in healthy subjects with high-normal glucose levels and in subjects with pre-diabetes. Cardiovasc Diabetol 2011, 10:30.

15. Plichart M, Empana JP, Lambert JC, Amouyel P, Tiret L, Letenneur L, Berr C, Tzourio C, Ducimetiere P: Single polymorphism nucleotide rs 1333049 on chromosome 9p21 is associated with carotid plaques but not with common carotid intima-media thickness in older adults. A combined analysis of the Three-City and the EVA studies. Atherosclerosis 2012, 222(1):187-190

16. Bown MJ, Braund PS, Thompson J, London NJ, Samani NJ, Sayers RD: Association between the coronary artery disease risk locus on chromosome 9p21.3 and abdominal aortic aneurysm. Circ Cardiovasc Genet 2008, 1(1):39-42.

17. Dandona S, Stewart AF, Chen L, Williams K, So D, O'Brien E, Glover C, Lemay M, Assogba O, Vo L, et al: Gene dosage of the common variant 9p21 predicts severity of coronary artery disease. J Am Coll Cardiol 2010, 56(6):479-486.

18. Bjorck HM, Lanne T, Alehagen U, Persson K, Rundkvist L, Hamsten A, Dahlstrom U, Eriksson P: Association of genetic variation on chromosome 9p21.3 and arterial stiffness. J Intern Med 2009, 265(3):373-381.

19. Alberti $K G$, Zimmet $P$, Shaw J: The metabolic syndrome-a new worldwide definition. Lancet 2005, 366(9491):1059-1062.

20. Ma WY, Li HY, Hung CS, Lin MS, Chiu FC, Lin CH, Shih SR, Chuang LM, Wei $J \mathrm{~N}$ : Metabolic syndrome defined by IDF and AHA/NHLBI correlates better to carotid intima-media thickness than that defined by NCEP ATP III and WHO. Diabetes Res Clin Pract 2009, 85(3):335-341.

21. Detchaporn P, Kukongviriyapan U, Prawan A, Jetsrisuparb A, Greenwald SE, Kukongviriyapan V: Altered vascular function, arterial stiffness, and antioxidant gene responses in pediatric thalassemia patients. Pediatr Cardiol 2012, 33(7):1054-1060.

22. Cameron JD, Cruickshank JK: Glucose, insulin, diabetes and mechanisms of arterial dysfunction. Clin Exp Pharmacol Physiol 2007, 34(7):677-682.

23. Greenwald SE: Ageing of the conduit arteries. J Pathol 2007, 211(2):157-172.

24. Stehouwer $C D$, Henry RM, Ferreira I: Arterial stiffness in diabetes and the metabolic syndrome: a pathway to cardiovascular disease. Diabetologia 2008, 51(4):527-539. 
25. Wassink AM, Olijhoek JK, Visseren FL: The metabolic syndrome: metabolic changes with vascular consequences. Eur J Clin Invest 2007, 37(1):8-17.

26. Tsuchikura S, Shoji T, Kimoto E, Shinohara K, Hatsuda S, Koyama H, Emoto $M$, Nishizawa Y: Central versus peripheral arterial stiffness in association with coronary, cerebral and peripheral arterial disease. Atherosclerosis 2010, 211(2):480-485.

27. Van Bortel LM, Laurent S, Boutouyrie P, Chowienczyk P, Cruickshank JK, De Backer T, Filipovsky J, Huybrechts S, Mattace-Raso FU, Protogerou AD, et al: Expert consensus document on the measurement of aortic stiffness in daily practice using carotid-femoral pulse wave velocity. J Hypertens 2012, 30(3):445-448.

28. Sugawara J, Hayashi K, Yokoi T, Tanaka H: Age-associated elongation of the ascending aorta in adults. JACC Cardiovasc Imaging 2008, 1(6):739-748.

29. Wenn CM, Newman DL: Arterial tortuosity. Australas Phys Eng Sci Med 1990, 13(2):67-70.

30. Youn JC, Kim JY, Park S, Kwon J, Lee HS, Shin DH, Lee SH, Kang SM, Hoon Son $\mathrm{N}$, Jang $\mathrm{Y}$ : Comparison of arterial stiffness indices measured by the Colins and SphygmoCor systems. Hypertens Res 2012, 35(12):1180-1184.

31. Deng $L H$, Huang $R, W u Z L, X u D L$ : [Value of $C$-reactive protein in the diagnosis of arteriosclerosis in patients with essential hypertension]. Nan Fang Yi Ke Da Xue Xue Bao 2009, 29(3):521-524.

32. Ye S, Willeit J, Kronenberg F, Xu Q, Kiechl S: Association of genetic variation on chromosome $9 p 21$ with susceptibility and progression of atherosclerosis: a population-based, prospective study. J Am Coll Cardiol 2008, 52(5):378-384.

33. Horne BD, Carlquist JF, Muhlestein JB, Bair TL, Anderson JL: Association of variation in the chromosome 9p21 locus with myocardial infarction versus chronic coronary artery disease. Circ Cardiovasc Genet 2008, 1(2):85-92.

34. Wang W, Peng W, Zhang X, Lu L, Zhang R, Zhang Q, Wang L, Chen Q, Shen W: Chromosome 9p21.3 polymorphism in a Chinese Han population is associated with angiographic coronary plaque progression in nondiabetic but not in type 2 diabetic patients. Cardiovasc Diabetol 2010, 9:33.

35. Buysschaert I, Carruthers KF, Dunbar DR, Peuteman G, Rietzschel E, Belmans A, Hedley A, De Meyer T, Budaj A, Van de Werf F, et al: A variant at chromosome 9 p21 is associated with recurrent myocardial infarction and cardiac death after acute coronary syndrome: the GRACE Genetics Study. Eur Heart J 2010, 31(9):1132-1141.

36. Pasmant E, Sabbagh A, Vidaud M, Bieche I: ANRIL, a long, noncoding RNA, is an unexpected major hotspot in GWAS. FASEB J 2011, 25(2):444-448.

37. Kalinina N, Agrotis A, Antropova Y, llyinskaya O, Smirnov V, Tararak E, Bobik A: Smad expression in human atherosclerotic lesions: evidence for impaired TGF-beta/Smad signaling in smooth muscle cells of fibrofatty lesions. Arterioscler Thromb Vasc Biol 2004, 24(8):1391-1396.

38. Schunkert H, Gotz A, Braund P, McGinnis R, Tregouet DA, Mangino M, Linsel-Nitschke P, Cambien F, Hengstenberg C, Stark K: Repeated replication and a prospective meta-analysis of the association between chromosome 9p21.3 and coronary artery disease. Circulation 2008, 117(13):1675-1684.

39. Samani NJ, Schunkert H: Chromosome 9p21 and cardiovascular disease: the story unfolds. Circ Cardiovasc Genet 2008, 1(2):81-84.

40. Biros E, Cooper M, Palmer L, Walker PJ, Norman PE, Golledge J: Association of an allele on chromosome 9 and abdominal aortic aneurysm. Atherosclerosis 2010, 212(2):539-542

\section{doi:10.1186/1475-2840-12-93}

Cite this article as: Phababpha et al: Association of arterial stiffness with single nucleotide polymorphism rs1333049 and metabolic risk factors. Cardiovascular Diabetology 2013 12:93.

\section{Submit your next manuscript to BioMed Central and take full advantage of:}

- Convenient online submission

- Thorough peer review

- No space constraints or color figure charges

- Immediate publication on acceptance

- Inclusion in PubMed, CAS, Scopus and Google Scholar

- Research which is freely available for redistribution

Submit your manuscript at www.biomedcentral.com/submit 